Abstracta Iranica Abstanica

Revue bibliographique pour le domaine irano-aryen

Volume 28 | 2007

Comptes rendus des publications de 2005

«The Letters of Eljigidei, Hülegü, and Abaqa:

Mongol Overtures or Christian Ventriloquism?».

Inner Asia, 7, 2005, pp. 143-62.

Marie Favereau

(2) OpenEdition

Journals

Édition électronique

URL : http://journals.openedition.org/abstractairanica/17302

DOI : 10.4000/abstractairanica. 17302

ISSN : 1961-960X

Éditeur :

CNRS (UMR 7528 Mondes iraniens et indiens), Éditions de l'IFRI

Édition imprimée

Date de publication : 15 mai 2007

ISSN : 0240-8910

Référence électronique

Marie Favereau, « «The Letters of Eljigidei, Hülegü, and Abaqa: Mongol Overtures or Christian

Ventriloquism? ». Inner Asia, 7, 2005, pp. 143-62. », Abstracta Iranica [En ligne], Volume 28 | 2007,

document 149, mis en ligne le 18 septembre 2007, consulté le 25 septembre 2020. URL : http://

journals.openedition.org/abstractairanica/17302; DOI : https://doi.org/10.4000/abstractairanica.

17302

Ce document a été généré automatiquement le 25 septembre 2020.

Tous droits réservés 


\title{
« The Letters of Eljigidei, Hülegü, and Abaqa: Mongol Overtures or Christian Ventriloquism? ». Inner Asia, 7, 2005, pp. 143-62.
}

\author{
Marie Favereau
}

1 L'A. réunit dans cet article trois lettres qui ont la particularité d'avoir été envoyées à l'initiative des Mongols. La première, adressée par un représentant (Eljigidei) du grand khan au roi de France, date de 1248, la deuxième fut envoyée par l'Ilkhan Hülegü au roi de France, Louis IX eb 1262 et la troisième fut expédiée en 1274 par l'Ilkhan Abaqa à l'intention du Pape Grégoire X et des souverains d'Occident. D.A. montre comment les Mongols de Perse, dans leur tentative d'alliance avec la chrétienté contre les Mamelouks et la Horde d'Or, élaborent un véritable discours diplomatique. Pour savoir si ce discours fut entendu et si ces deux mondes entrèrent réellement en communication, l'auteur propose de comparer les textes originaux des lettres et leurs traductions. En suivant le fil du " prêtre Jean ", cette figure du christianisme sise entre mythe et réalité, D.A. cherche les meilleures pistes pour approfondir la question de la différence culturelle et de la complexité d'une alliance qui doit passer par le crible d'une inter-compréhension du discours diplomatique. Cette image du roi chrétien n'est pas perçue de manière unilatérale - ce que les uns veulent signifier par "prêtre Jean ", n'est pas ce que les autres entendent par la même expression - et dans l'usage diplomatique, elle varie selon les alliances politiques. Dans les missives mongoles, elle apparaît ainsi comme la métaphore d'un certain rapport à la chrétienté. Mais était-elle fondée sur les mêmes références historiques et mythologiques? Sur les mêmes espérances?

L'A. relance le débat sur la, ou plutôt, les langues écrites utilisées par les khans et sur l'usage du mongol dans les échanges avec les États latins. L'importance grandissante du persan comme langue d'administration et de diplomatie est une donnée à prendre en compte dès les premiers temps de l'Empire mongol. Enfin, D.A. attire notre attention 
sur le rôle fondamental de l'interprète-traducteur qui signe, dans l'espace médian entre expéditeur et destinataire, le premier acte de la diplomatie. Cette tâche était très souvent confiée à des chrétiens orientaux qui maîtrisaient les langues latine et persane. Ainsi, ils eurent une influence déterminante dans l'établissement de la politique extérieure ilkhanide et dans l'émulation qui émanait de l'idée d'alliance avec la chrétienté occidentale.

Le contenu des lettres prouve que les khans étaient capables d'assouplir leur discours en fonction des réalités politiques tout en respectant les règles de la tradition gengiskhanide. L'Ilkhan ne pouvant se cantonner comme le grand khan à un discours de toute puissance, des nuances apparaissent dans les textes diplomatiques qui laissent entrevoir les premiers pas d'une administration naissante. La capacité à s'adapter à la langue, la culture, la religion du destinataire pour en être compris le mieux possible témoignent d'un réel désir de s'entendre, d'une "nécessité d'alliance » dans une conjoncture moins favorable à la puissance mongole (notamment depuis la victoire des Mamelouks à 'Ayn Jālūt en 1260). Ainsi, l'évolution du discours ilkhanide traduit-elle celle du jeu politique international : les Mongols, cherchant à s'adapter à une situation où ils se sentent affaiblis, créent les prémices d'une véritable diplomatie. Mais ils se heurtent aux difficultés d'un monde à deux vitesses : comment construire une politique étrangère à long terme quand la brièveté des règnes et la durée des voyages rendent caducs courriers et ambassades?

\section{INDEX}

Thèmes : 4.1. Histoire médiévale

\section{AUTEURS}

MARIE FAVEREAU

IFAO - Le Caire 